\title{
ESTIMATION OF OXYGEN CYLINDER AVAILABILITY AND CLASSIFICATION OF ITS TYPES, SUITABILITY USING MACHINE LEARNING AND DATA ANALYSIS
}

\author{
ANURAG SINHA \\ DEPARTMENT OF INFORMATION TECHNOLOGY, AMITY UNIVERSITY JHARKHAND, RANCHI 834001
}

\begin{abstract}
This is break direction on oxygen sources and conveyance methodologies for COVID-19 treatment. It has been adjusted from WHO and UNICEF's specialized details and direction for oxygen treatment gadgets, which is important for the WHO clinical gadget specialized arrangement, 1 and depends on current information on the circumstance in China and different nations where cases have been distinguished. This direction is proposed for wellbeing office chairmen, clinical leaders, acquisition officials, arranging officials, biomedical architects, foundation engineers and strategy producers. It portrays how to: measure oxygen interest, to distinguish oxygen sources that are accessible, and select suitable flood sources to best react to COVID-19 patients' requirements, particularly in low-and-center pay nations. WHO will refresh these suggestions as new data opens up. Coronavirus pandemic spurred fake interest for oxygen gas chambers for clinical use - both at emergency clinics and inquisitively, for home use by patients. A few patients and surprisingly sound people investigate the conceivable outcomes and likely benefits of utilizing oxygen from chambers for private utilization. Be that as it may, this isn't continuously protected, and sufficient safety measures are to be taken, bombing which there can be fatalities. This paper investigates the significance of keeping up satisfactory degrees of oxygen levels appropriate for human utilization. It advises the clinical use and the advantages and disadvantages of putting away oxygen chambers at home. The investigation likewise addresses lawful and administrative perspectives. The investigation's discoveries can help people settle on an educated choice on the protected use regarding oxygen gas. Further, it cautions on the expanded significance of guidelines and limiting access and use. This paper aims at designing an oxygen level monitoring technique in an oxygen cylinder. The amount of oxygen present inside the oxygen cylinder is very vital information when such cylinder is in use for supply of oxygen to a critical patient. The amount of oxygen present inside the cylinder is measured by the pressure at the outlet nozzle. The pressure is measured using a high precision MEMS Pressure Sensor. The output of the MEMS pressure sensor is voltage of the order milli. An amplifier is used to amplify this milli volt signal. A microcontroller is used in cascade to process the signal and display the pressure of oxygen cylinder.
\end{abstract}

Keywords- covid-19, machine learning, oxygen cylinder. 


\section{Introduction}

Governments across the world went to health related crises set off by the COVID-19 pandemic. Like a few different nations, India, the second-most crowded nation, fought for ideal utilization of clinical foundations, for example, clinic beds, clinical oxygen, and others [1]. This pandemic required various types of office to deal with patients from distance [2] while forecast of lockdown period additionally had significance as examined [3].

Aside from its modern utilization, oxygen is utilized for different clinical purposes - from general medication organization to clinical help and crisis systems. Oxygen is a basic component for human existence presence, and on account of its characteristic accessibility through the air, it is some of the time neglected to be a day to day existence saving fundamental medication. The ideal accessibility of clinical oxygen is a decider of life and demise for the patient. Emergency clinics are continually giving need over the rest with respect to the persistent accessibility of clinical oxygen. Clinical Oxygen is a basic fixing in treating certain basic ailments like pneumonia, intestinal sickness, sepsis, and meningitis. Youngsters and moms are frequently directed clinical oxygen to ease breathing when their lives are in danger during clinical treatment. Its significance once developed seriously during the COVID-19 pandemic in view of its nearby relationship with the respiratory framework [4]. High-stream nasal oxygen is discovered to be a protected and productive treatment for COVID-19 patients who are not in an ICU [5]. The WHO says that $15 \%$ of COVID-19 patients require clinical oxygen due to breathing troubles [6]. Quiet hypoxia patients don't show any apparent respiratory trouble yet experience unexpected perilously low oxygen levels [7]. NIH suggests high-stream nasal cannula (HFNC) oxygen over non-intrusive positive pressing factor ventilation (NIPPV) [8]. Some fundamentally sick patients even require a ventilator. Notwithstanding, the accessible number of ventilators is excessively low. This constrained clinical gear makers to rapidly go into creation mode.

Coronavirus obviously uncovered a significant shortcoming in the wellbeing frameworks - that of clinical oxygen creation and conveyance [9]. In spite of organizations attempting to put forth a valiant effort to supply clinical oxygen, request surpassed the stock, making its accessibility lacking during the pandemic occasions. Some advanced strategies, for example, on location clinical oxygen creation utilizing oxygen generators, are tested. Such arrangement empowers nonstop, dependable, and practical stock for portable and static medication. They are extraordinarily planned and created to supply oxygen in clinical offices following exacting quality rules. These generators satisfy worldwide quality guidelines and give virtue of 93 to 95 percent. On account of Industry 4.0 principles, far off checking, and activity of the clinical oxygen age frameworks should be possible from a PC workstation, tablet, or cell phone from anyplace on the planet [10]. Brilliant plants can help in improving the blower room rehearses at the assembling unit [9].

Emergency clinics obtain clinical oxygen through chambers that fill it at modern gas plants. The chambers are introduced in the emergency clinic cellar or at nearness and funneled to the patient's bed. The patients are charged dependent on utilization. Regularly, a $\$ 40-\$ 60$ would be charged for an extreme pneumonia kid who burns through 3-4 days and customers 4,000 to 8,000 cubic liters of oxygen. The test for clinical and wellbeing organization is to build the stockpile of clinical oxygen while diminishing expense with the goal that it is available where it is required generally, free at the place of utilization. This requests expanded speculation and obligation to put oxygen foundation at the focal point of widespread wellbeing inclusion techniques [4].

The majority of the COVID beds in emergency clinics overall confronted an abrupt interest for channeled oxygen supply compelling clinic organizations to spend more to supply copper funneled oxygen associated with a chamber bank. The worldwide stock of oxygen is in the possession of moderately few corporates [11]. However much $80 \%$ of the stockpile is through a modest bunch number of providers. The market size which was just about $\$ 5$ billion of every 2019 is guage to turn into a $\$ 8$ billion market by 2026. Because of the frenzy prerequisite, mechanical oxygen 
chambers are requested to change over into clinical oxygen, and orders were set for additional chambers. The circumstance required more non-budgetary spending by clinics.

\section{Coronavirus and oxygen}

Information from China recommends that albeit most of individuals with COVID-19 have gentle ailment (40\%) or moderate sickness (40\%); around $15 \%$ of them have serious disease requiring oxygen treatment, and $5 \%$ will be basically sick requiring emergency unit. Likewise, most fundamentally sick COVID-19 patients will require mechanical ventilation. 2,3 For these reasons, COVID-19 treatment medical services offices ought to be furnished with heartbeat oximeters, working oxygen frameworks including single-use oxygen conveyance interfaces.

Oxygen treatment is suggested for all serious and basic Coronavirus patients, with low portions going from 1-2 $\mathrm{L} / \mathrm{min}$ in youngsters and beginning at $5 \mathrm{~L} / \mathrm{min}$ in grown-ups with nasal cannula, moderate stream rates for use with venturi cover $(6-10 \mathrm{~L} / \mathrm{min})$; or on the other hand higher stream rates $(10-15 \mathrm{~L} / \mathrm{min})$ utilizing a veil with supply pack. Also, oxygen can be conveyed at higher stream rates and in higher focuses, utilizing high-stream nasal cannula (HFNC) gadgets, non-intrusive ventilation (NIV) and intrusive ventilation devices.4 Contrasted and standard oxygen treatment, HFNC and NIV gadgets may decrease the requirement for intubation, 5 which might be a thought in settings where there is restricted accessibility of mechanical ventilation. In any case, HFNC and NIV gadgets. convey a danger of vaporized age and subsequently requiring airborne safeguards by the wellbeing laborers utilizing them.

Alert

- Oxygen upholds ignition.

The expansion of concentrated oxygen to a fire expands its power impressively and can even help the ignition of materials that ordinarily don't consume.

- Do not go close to any open flares when utilizing oxygen - Try not to smoke close to oxygen sources!

Oxygen sources Oxygen treatment or supplemental oxygen is the arrangement of clinical oxygen as a medical care intercession. Clinical oxygen contains in any event $82 \%$ unadulterated oxygen, is liberated from any pollution and is produced by a sans oil blower. Just excellent, clinical evaluation oxygen ought to be given to patients. Oxygen frameworks should comprise of an oxygen source, or creation joined with capacity. Regular oxygen sources are: oxygen creating plants and fluid oxygen in mass capacity tanks, and oxygen concentrators. The most well-known wellspring of oxygen stockpiling utilized in medical care settings is a chamber. The proper decision of oxygen source relies upon numerous factors, including: the measure of oxygen required at the treatment focus; the accessible framework, cost, limit also, store network for neighborhood creation of therapeutic gases; the dependability of electrical stockpile; and admittance to upkeep administrations and extra parts, and so forth Insights concernin oxygen-source choices are given in this direction, and in more profundity in WHO-UNICEF specialized determinations and direction for oxygen treatment gadgets.

Oxygen sources Oxygen therapy or supplemental oxygen is the provision of medical oxygen as a health-care intervention. Medical oxygen contains at least $82 \%$ pure oxygen, is free from any contamination and is generated by an oil-free compressor. Only high quality, medical-grade oxygen should be given to patients. Oxygen systems must consist of an oxygen source, or production combined with storage. Common oxygen sources are: oxygen generating plants and liquid oxygen in bulk storage tanks, and oxygen concentrators. The most common source of oxygen storage used in health-care settings is a cylinder. The appropriate choice of oxygen source depends on many factors, including: the amount of oxygen needed at the treatment centre; the available infrastructure, cost, capacity and supply chain for local production of medicinal gases; the reliability of electrical supply; and access to maintenance services and spare parts, etc. Details about these different oxygen-source options are provided in this guidance, and 
in more depth in WHO-UNICEF technical specifications and guidance for oxygen therapy devices. 1 Liquid oxygen plants: Cryogenically produced liquid oxygen is always generated off-site (not at a medical facility). Medical facilities can be equipped with large bulk liquid oxygen tanks that are refilled periodically by a truck from a supplier. The liquid oxygen tank supplies a centrally piped system throughout the health facility by self-vaporization and for which a power supply is not required. Although an economical option in some settings, the use of liquid oxygen relies on external supply chain mechanisms and needs a bit more caution with respect to transport and storage due to the risks associated with higher pressures. Extra care should be taken in more extreme environments. It is best practice to also have cylinders as a backup supply. 1 PSA oxygen plant: A pressure swing adsorption (PSA) oxygen plant serves as a large, central source of oxygen generation using PSA technology (similar to concentrators) that can be located on-site at medical facilities. Oxygen from a PSA plant can either be piped directly to bedside terminal units within patient areas or, with a booster compressor, be used to refill cylinders for oxygen distribution (either on-site or to neighbouring health facilities) or for Oxygen sources and distribution for COVID-19 treatment centres: interim guidance -2- backup oxygen supply. Oxygen plants require a reliable source of power. It is best practice to also have cylinders as a backup supply. Oxygen concentrators: An oxygen concentrator is a selfcontained, electrically powered medical device designed to concentrate oxygen from ambient air. An oxygen concentrator uses PSA technology to draw in air from the environment, removing the nitrogen to produce a continuous source of more than $90 \%$ concentrated oxygen. It should not be used if the oxygen concentration falls below $82 \%$. 1 Oxygen concentrators are portable and can be moved between clinical areas, but they are also often set up to be stationary fixtures in patient areas. Concentrators designed for portable medical support are available in models that can deliver maximum flow rates of between 5 and $10 \mathrm{~L} / \mathrm{min}$. When used with a flowmeter stand for splitting flow, concentrators can provide a continuous supply of oxygen to multiple patients at the same time. Concentrators can provide a safe and cost-effective source of oxygen, but they do require a source of continuous and reliable power and regular preventive maintenance to ensure proper functioning. It is best practice to also have cylinders as a backup supply.1 Oxygen storage and intra-hospital distribution Oxygen cylinders: Oxygen gas can be compressed and stored in cylinders. These cylinders are filled at a gas manufacturing plant, either via a cryogenic distillation or a PSA plant, 6 and then transported to health facilities. Cylinders can be used in one of two ways. One, by installing them directly within patient areas or, similar to direct piping and two, by connecting them to subcentral manifold systems (groups of cylinders linked in parallel) at the facility. Thus, oxygen can be piped to specific areas of the health facility, even at the ward level. When cylinders are the only source of oxygen in a health facility, a strong supply-chain is required to ensure ongoing availability. Once filled, cylinders themselves do not require electricity, but they do require several accessories and fittings to deliver oxygen, such as pressure gauges, regulators, flowmeters, and in some cases, humidifiers. Cylinders also require periodic maintenance, commonly provided by gas suppliers at the point of refilling. Additionally, storage or transportation of medical oxygen in cylinders must be done carefully and by trained personnel as the contents are under extreme pressure. Pipeline intrahospital distribution networks are helpful to supply oxygen at high pressure to equipment such as anaesthetic machines and ventilators. A key advantage of pipeline systems is that they obviate the need for handling and transporting heavy cylinders between hospital wards. However, the high cost and complexity of installing centralized oxygen sources with copper pipelines and the associated specialized maintenance required for this make pipeline systems less accessible for turn-key installations.

\section{LITERATURE REVIEW}

Long haul oxygen treatment (LTOT) is firmly recommended for constant obstructive aspiratory illness (COPD) and other serious hypoxemic lung sicknesses, for example, hypoxic persistent aspiratory illness. Versatile Oxygen Concentrators (POC) are the gadgets utilized by and large. Specialists proposed a few different ways of viably utilizing clinical oxygen. For instance,[3]suggests initial an underlying solution for $15 \mathrm{~h}$ or more each day followed by valuable training on oxygen treatment by a medical attendant or physiotherapist, necessity of end of smoking and the utilization of oxygen in every homegrown circumstance (latrine, suppers, furthermore, relaxation), and to gauge and discover the shortfall of results from oxygen treatment. For instance, serious consumes are accounted for due to 
smoking while at the same time interfacing oxygen conveyance gear. [4] Several risks like tobacco smoking, cooking, candles, family warming, open air, combustible materials, sparkles, and others could prompt danger.

[5] Equipment makers, oxygen gas chamber suppliers, and the fire wellbeing division frequently give handouts what's more, manuals that talk long about care to be taken with oxygen to forestall perils. The different advances incorporate doing a danger evaluation before establishment, about oxygen enhancement, care not to utilize materials that are contradictory with oxygen, not to utilize oxygen in hardware that isn't unequivocally intended for the reason, and other precautions.[6] Clinical oxygen gas being a medication, requires a solution for home use, chiefly when it is to be utilized for additional delayed utilization. For patients to whom it is endorsed, it is generally definitely more than discretionary. Regardless of this, guidance, directing, and schooling on its right utilization are scarcely given. [7]Another study found that patients on LTOT would in general overestimate their oxygen use, and worthy consistence was seen in $65 \%$ of the patients. [8] Research proposes that respiratory advisors (RTs) need to reliably assess patients hospitalized for COPD intensifications for home oxygen before release and that lone a minority are associated with choosing home oxygen equipment.[9] Even more than the patient, doctors should know the highlights of new and mechanically refreshed home oxygen treatment (HOT) gadgets. [10] While there is plentiful writing on the subject of oxygen chambers, this paper adds to our body on information on the comprehension of the use of chambers at home, for the most part when expanded energy is seen for their utilization at home in the midst of COVID-19 pandemic.

\section{OXYGEN LEVELS IN BLOOD}

Before a patient is controlled oxygen, the current levels of the blood vessel blood are first decided. A heartbeat oximeter is normally utilized for this. People can purchase a heartbeat oximeter from a neighborhood clinical gadget store or on the web store. In the working room, predominant quality heartbeat oximeters are utilized as a component of sedation methodology by anesthetists.[11]The oximeter can be cut to a finger and subsequently very easy to utilize and doesn't include gathering blood tests. Subsequently, it is speedy and nicely precise. The oxygen levels in the blood will typically be somewhere in the range of 95 and 100\%. Oxygen immersion levels under $90 \%$ can lead the patient to a condition called Hypoxemia. This outcomes quickly in constraining the patient to inhale all the more significantly, have a higher pulse, windedness, hacking, wheezing, perspiring, changes skin-shading, disarray among others. This condition requires the patient to look for sure fire clinical help.

\section{OXYGEN CONCENTRATION LEVELS and SIDE EFFECTS}

Oxygen is fundamental for breathing, yet the necessary fixation level of oxygen in encompassing air is a simple 19.5 percent.[12] Naturally, breathable air adrift level contains oxygen that is by and large adequate for the people. Nonetheless, the oxygen levels noticeable all around can drop if harmful gases noticeable all around increment. Word related Safety and Health Organization (OSHA) expresses the oxygen levels for people to inhale to be somewhere in the range of 19.5 and 23.5 percent. Table 1 shows the results when the oxygen level is lower (like loss of mental capacities) or if the levels go higher (muscle jerking, tissue, or cell harm) than the ideal levels.। 
Table 1: Side effects of oxygen deficiency exposure

\begin{tabular}{|l|l|}
\hline Oxygen concentration (\% vol) & Effect of the health of a person while resting \\
\hline 19 & $\begin{array}{l}\text { Some adverse physiological effects occur, but they may not be } \\
\text { noticeable. }\end{array}$ \\
\hline $15-19$ & $\begin{array}{l}\text { They have impaired thinking and attention, increased pulse, and } \\
\text { breathing rate. Reduced coordination and decreased the ability to } \\
\text { work strenuously. It reduced physical and intellectual performance } \\
\text { without awareness. }\end{array}$ \\
\hline $12-15$ & $\begin{array}{l}\text { Poor judgment. Faulty coordination. Abnormal fatigue upon } \\
\text { exertion. Emotional upset. }\end{array}$ \\
\hline $10-12$ & $\begin{array}{l}\text { Abysmal judgment and coordination, Impaired respiration that can } \\
\text { cause permanent heart damage. Possibility of fainting within a few } \\
\text { minutes without warning. Nausea and vomiting. }\end{array}$ \\
\hline Less than 10 & $\begin{array}{l}\text { Inability to move and to faint almost immediately. Loss of } \\
\text { consciousness. Convulsions. Death. }\end{array}$ \\
\hline
\end{tabular}

Oxygen is our essential life-support. The air we inhale is so indispensable that without it we would quickly pass on. Clean air is comprised of a few gases of which Oxygen is the most critical to us. Clean air contains 19\%-21\% Oxygen. The age and upkeep of all our body measures are upheld by four fundamental life-support parts: carbs, water, proteins and energy. Most Scientists concur that oxygen is really the abrogating key fixing in every one of the four life-support segments. The oxygen focus in a solid human body is around multiple times than that of air. At the point when body oxygen tumbles to very low levels for delayed timeframes, the body may turn into a rearing ground for destructive microorganisms, infections, growths, parasites and other irresistible specialists. A large portion of these are anaerobic, for example they can't live in an oxygen-rich climate. Some exploration shows that when the oxygen substance of the body is inside the ordinary level, irresistible microorganisms possess a more troublesome energy for rearing and duplicating. The halfway pressing factor of oxygen in ordinary blood ought to be around $97 \%$. Inside every red platelet there are iron-rich hemoglobin particles. Around $97 \%$ of the oxygen conveyed to the cells is joined to these hemoglobin particles and 3\% of the oxygen supply disintegrated in the blood plasma. At the point when the blood oxygen levels stay low for broadened timeframes, the cells can't get a sufficient and predictable inventory of oxygen and there might be trouble in opposing the attack of microorganisms bringing about diminishing of normal life-support [1]-[4]. Under the present condition when lungs of a human body neglect to take suitable measure of oxygen inside the body, an oxygen chamber is utilized to siphon oxygen to the human body. In this way proper plan for supply of oxygen from an oxygen chamber can be named as one of the live saving gadget. It is vital to consistently screen the situation with such gadgets. Occasional it is seen that the measure of oxygen contains inside the chamber is undetected. At the point when the patient's feels awkward because of non accessibility of oxygen in chamber, out of nowhere there are surges and may prompt extreme outcomes.

So this paper proposes a strategy which will monitor the oxygen levels halfway in the chambers present in a medical clinic. It likewise does the nearby estimation of oxygen level in the chamber and a ringer blares when the oxygen level in the oxygen chamber is dipped under a pre-chosen esteem so that orderly of a patient can be ready alongside working medical caretakers and ward young men for extra reinforcement. For this reason a MEMS pressure sensor is utilized to quantify the pressing factor followed by an enhancer to intensify the yield of MEMS pressure sensor. The yield of intensifier is shipped off a microcontroller to deal with the sign and show the genuine pressing factor what's more, a ringer signals when the pressing factor dips under a predefined lower level. Further, oxygen level is too sent to the checking station utilizing remote correspondence to monitor the situation with the chambers.

Since the oxygen chamber is compact, the force required for the proposed gadget is gotten from a battery. It is significant to screen the state of battery; this is additionally taken consideration in the proposed method. At the observing station LabVIEW 


\section{Experiment}

\subsection{Destinations of the examination}

Key destinations of the examination are:

1. to inform on the abrupt interest for clinical oxygen gas that emerged during the pandemic circumstance.

2. comprehend the coordination of different partners like the Governments, oxygen providers, and clinics during the unexpected circumstance.

\subsection{Examination procedure}

Information from auxiliary sources like definitive sites (WHO among others), emergency clinics, clinical hardware suppliers, oxygen suppliers, government bodies, controllers, media, and research diaries are gathered and detailed in this investigation.

\subsection{Results and conversation}

The Petroleum and Explosives Safety Organization (PESO) is the body that security in assembling/refining, stockpiling, transportation, taking care of, and utilization of dangerous substances [12]. It runs under the Department of Promotion of Industry and Internal Trade of the Ministry of Commerce and Industries of the Indian Government. In 2020, PESO reported a progression of new/alterations to a few principles and notices to encourage the speedy and safe vehicle of clinical oxygen gas. During the pandemic occasions, the Central Government and PESO were in consistent coordination with the State Government units, (for example, the District Collectorates, the Drug Control Administration (DCA), among others). These neighborhood units, thus, have set up a coordination framework at the District Level. Inferable from expanded reports of misbehaviors, PESO gave orders demanding keeping up the everyday record of filling, stockpiling, and dispatch of chambers and submitting reports.

The District Collectors at the District level are enabled to settle on singular choices, for example, planning supply plans, consequently defending the stock of chambers to different areas and emergency clinics as indicated by need and desperation. While the specialists arranged the stock timetables, the end client (like clinics) would be taking care of the bill. Oxygen information accessibility status reports from different oxygen providers are refreshed every day to the District authority, who thusly synchronizes at the state-level.

The Center for Global Development (CGD) featured the requirement for an offset in quick necessities with long haul cost-viability because of an increment in oxygen requests because of COVID-19. The note gave contemplations to setting up fluid oxygen tanks, PSA oxygen plants, oxygen chambers, and oxygen concentrators [14]. Having drawn from China's encounters, even the WHO gave comparative between time direction in regards to oxygen sources and dissemination for treatment focuses [13]. Inferable from the pandemic, oxygen fabricating framework for modern use was redirected for clinical purposes. This adversely affected the inventory and accessibility of gas for iron and steel cutting, warm plants, and railroad track projects. Be that as it may, the choice may be essential attributable to the health related crisis. Cryogenic Distillation Plants that utilization fluid oxygen can get above 99.5 percent unadulterated oxygen, while the oxygen age plant utilizes air, packs it, and cleans it to remove $93 \%$ oxygen. Taking a gander at the oxygen interest, the Central Government took up the onus of securing oxygen chambers during the pandemic's beginning phases and conveyed them to states. The principles overseeing the import of fluid oxygen from different nations were changed. Independently, inferable from the crisis circumstance, the endorsement of ISO 
Tank Container for homegrown development works with the quick and safe development of fluid oxygen in the country. Partners envious to import/transport fluid oxygen in ISO Tank Container are permitted to submit Application Form in AS-4, and endorsement inside $48 \mathrm{~h}$ was allowed. Consents and Generated Standard Operating Procedures (SOP) were given to change over modern oxygen chambers and surprisingly non-poisonous, noncombustible chambers to store and supply restorative oxygen. Emergency clinics were permitted to introduce cryogenic fluid big haulers so fluid oxygen (that is less massive) can be utilized, in this manner lessening the hanging tight an ideal opportunity for oxygen gas chamber providers to renew. Clinics without a doubt comprehended the requirement for contributing and introducing chambers and big haulers. Obviously, this speculation isn't just for COVID use yet will stay a commendable framework venture for the clinic. Indeed, even certain arrangements of the Motor Vehicles Act, 1988 are loose for transport vehicles that will be utilized solely for the carriage of oxygen during COVID-19 up to March 31, 2021 [15].

Regardless of mid-October 2020, the interest levels for clinical oxygen gas and the quantity of patients requiring clinical oxygen gas have given no indications of easing back down. Be that as it may, there was a geographic change popular. During the pandemic's pinnacle, states like Punjab, for instance, have looked for fluid oxygen supplies from neighbors, for example, Himachal Pradesh and Uttarakhand [17]. In the interim, different areas in the province of Maharashtra have effectively set up their oxygen plants. Others went into the authoritative freedom measures for setting up quickly. Upwards of 14 areas have set up their plants while 16 different regions have called for tenders for setting them. The state has two significant providers - Inox Air Products (four plants at Raigad, Pune, and Nagpur) and Linde India (two plants at Raigad and Thane) with a joined 800 metric ton fluid limit oxygen consistently. Corporates with in-house oxygen fabricating offices, for example, JSW Steel's Mangaon office in Pune, approached to give oxygen to medical clinics that required it.

Further, the Government coordinated the Electricity Department not to cut force supply for oxygen make plants. A few areas (like Latur and Beed) needed to cut between locale transportation of oxygen gas as the actual region required it [16]. Madhya Pradesh has removed the oxygen supply for manufacturing plants and redirected it for clinical purposes. North India started to report a higher number of cases at later part contrasted with Middle and South India. The elements are inverse in the beginning phases of the pandemic. The change popular levels required the exchange of fluid cryogenic big haulers and chambers to be moved from states with lesser interest than those requiring more. The Central Government took up all the coordination movement and permitted the states to help one another. The Government alarmed the All-India Industrial Gases Manufacturers' Association (AIIGMA) that Liquid Medical Oxygen being sold as Industrial Oxygen subsequent to paying 12\% GST. The demonstration is unlawful, untrustworthy, and a misfortune to the exchequer. 
Liquid Oxygen Production at Air Separation Plant

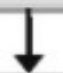

Filling Liquid Oxygen into Cryogenic Storage Vessel

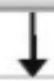

Transfer of Liquid Oxygen into Cryogenic Transport Vessel

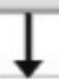

Decantation of Liquid Oxygen into Cryogenic Storage Vessel at

Liquid Compression Station

Conversion Process at Liquid Oxygen Compression Station

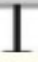

Fig 1Flowchart explaining the stages of the Oxygen supply process.

\subsection{0}

\subsection{0}

5000.000

4000.000

3000.000

2000.000

1000,000

0.000

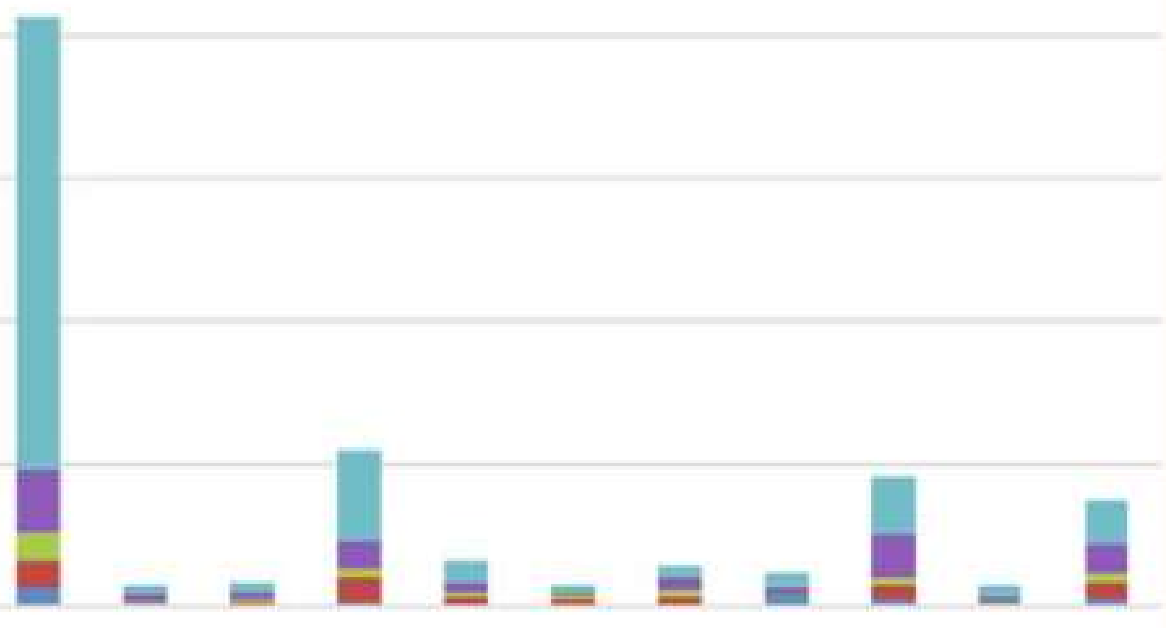

FIG 2 GRAPH OF COVERAGE OF CYLINDER 


\section{PROPOSED APPROACH}

Neural Network (or Artificial Neural Network) has the ability to learn by examples. ANN is an information processing model inspired by the biological neuron system. It is composed of a large number of highly interconnected processing elements known as the neuron to solve problems. It follows the non-linear path and process information in parallel throughout the nodes. A neural network is a complex adaptive system. Adaptive means it has the ability to change its internal structure by adjusting weights of inputs. (Source)

The neural network was designed to solve problems which are easy for humans and difficult for machines such as identifying pictures of cats and dogs, identifying numbered pictures. These problems are often referred to as pattern recognition. Its application ranges from optical character recognition to object detection.

Prologue to Neural Network

In 1943, Warren McCulloch and Walter Pitts built up the principal numerical model of a neuron. In their examination paper "A sensible analytics of the thoughts inborn in anxious movement", they depicted the basic numerical model for a neuron, which addresses a solitary cell of the neural framework that takes inputs, measures those sources of info, and returns a yield. This model is known as the McCulloch-Pitts neural model. (Source) NN is calculations are motivated by the human cerebrum to plays out a specific undertaking or capacities. NN perform calculations through an interaction by learning. The neural organization is a bunch of associated input/yield units in which every association has a weight related with it. In the learning stage, the organization learns by changing the loads to anticipate the right class name of the given sources of info.

The human cerebrum comprises of billions of neural cells that cycle data. Each neural cell thought about a basic handling framework. The Interconnected snare of neurons known as organic neural organization sends data through electrical signs. This equal intuitive framework makes the cerebrum to think and deal with data. Dendrites of a neuron get input signals from another neuron and react yield dependent on those contributions to an axon of some other neuron. In view of those data sources, fire a yield signal through an axon.

\section{Feedforward and Feedback Artificial Neural Networks}

There are two principle sorts of fake neural organizations: Feedforward and criticism fake neural organizations. Feedforward neural organization is an organization which isn't recursive. Neurons in this layer were simply associated with neurons in the following layer, and they are don't shape a cycle. In Feedforward signals travel just a single way towards the yield layer. (Source)

Input neural organizations contain cycles. Signs travel in the two ways by presenting circles in the organization. The criticism cycles can cause the organization's conduct change after some time dependent on its information. Criticism neural organization otherwise called intermittent neural organizations. (Source)

\section{Actuation Functions}

Actuation work characterizes the yield of a neuron regarding a nearby prompted field. Enactment capacities are a solitary line of code that gives the neural nets non-linearity and expressiveness. There are numerous actuation capacities. Some of them are as per the following (Source):

Personality work is a capacity that guides contribution to a similar yield esteem. It is a direct administrator in vector space. Likewise, realized straight line work where actuation is relative to the information. 
In Binary Step Function, if the worth of Y is over a specific worth known as the edge, the yield is True(or initiated), and assuming it's not exactly the edge, the yield is bogus (or not enacted). It is valuable in the classifier. Sigmoid Function called S-formed capacities. Strategic and exaggerated digression capacities are generally utilized sigmoid capacities. There are two sorts of sigmoid capacities. Twofold Sigmoid Function is a strategic capacity where the yield esteems are either double or shift from 0 to 1 . Bipolar Sigmoid Function is a strategic capacity where the yield esteem differs from - 1 to 1 . Otherwise called Hyperbolic Tangent Function or tanh. Slope Function: The name of the incline work is gotten from the presence of its chart. It maps negative contributions to 0 and positive contributions to a similar yield. ReLu represents the amended straight unit (ReLU). It is the most utilized enactment work on the planet. It yield 0 for negative upsides of $\mathrm{x}$.

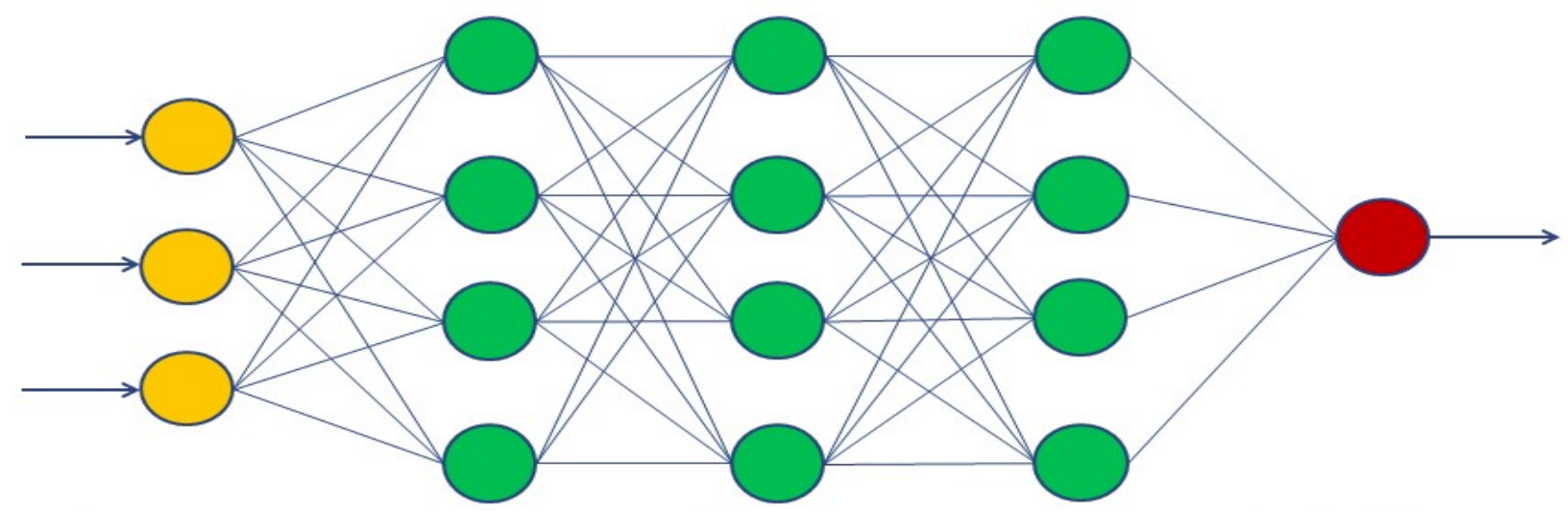

Input Layer

Hidden Layers

Output Layer

Hyper Tangent Function

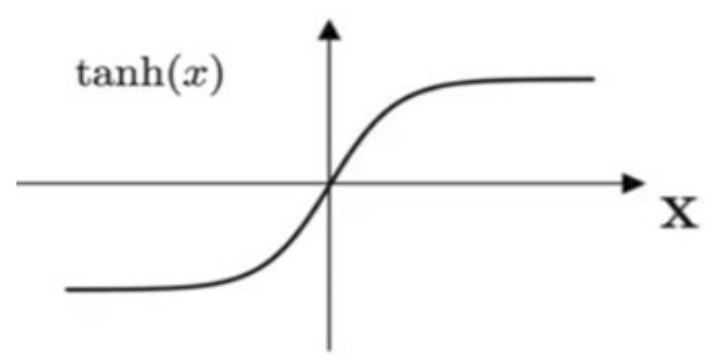

Sigmoid Function

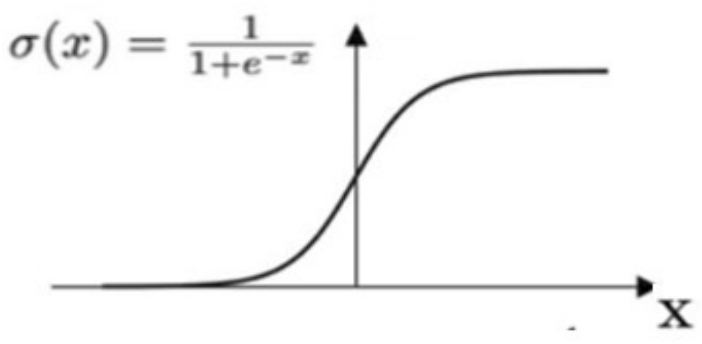

ReLU Function

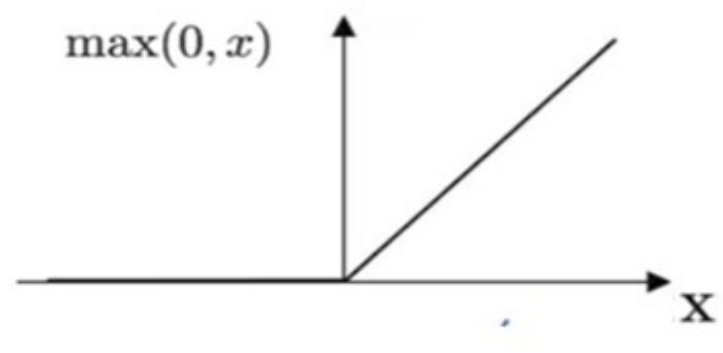

Identity Function

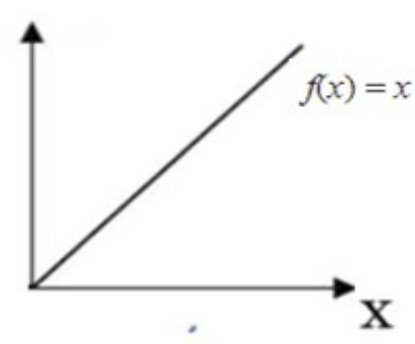




\section{Implementation of a Neural Network in $\mathbf{R}$}

\section{Install required package}

Let's first install the neuralnet library:

\# install package

install.packages("neuralnet")

Updating HTML index of packages in '.Library'

Making 'packages.html' ... done

\section{Create training dataset}

\begin{tabular}{|ccc}
\hline $\begin{array}{l}\text { Technical } \\
\text { Knowledge Score }\end{array}$ & $\begin{array}{l}\text { Communication } \\
\text { Skills Score }\end{array}$ & Student Placed \\
\hline 20 & 90 & Placed \\
\hline 10 & 20 & Not Placed \\
\hline 30 & 40 & Not Placed \\
\hline 20 & 50 & Not Placed \\
\hline 80 & 50 & Placed \\
\hline 30 & 80 & Placed
\end{tabular}

Let's create your own dataset. Here you need two kinds of attributes or columns in your data: Feature and label. In the table shown above, you can see the technical knowledge, communication skills score and placement status of the student. So the first two columns(Technical Knowledge Score and Communication Skills Score) are features and third column(Student Placed) is the binary label.

\# creating training data set

$\mathrm{TKS}=\mathrm{c}(20,10,30,20,80,30)$

$\mathrm{CSS}=\mathrm{c}(90,20,40,50,50,80)$

Placed $=\mathrm{c}(1,0,0,0,1,1)$

\# Here, you will combine multiple columns or features into a single set of data

$\mathrm{df}=$ data.frame(TKS,CSS,Placed)

Let's build a NN classifier model using the neuralnet library. 
First, import the neuralnet library and create NN classifier model by passing argument set of label and features, dataset, number of neurons in hidden layers, and error calculation.

\# load library

require(neuralnet)

\# fit neural network

$\mathrm{nn}=$ neuralnet $($ Placed $\sim \mathrm{TKS}+\mathrm{CSS}, \mathrm{data}=\mathrm{df}$, hidden $=3$, act.fct $=$ "logistic", linear.output $=$ FALSE)

Here,

- Placed $\sim$ TKS + CSS, Placed is label annd TKS and CSS are features.

- $\mathrm{df}$ is dataframe,

- hidden=3: represents single layer with 3 neurons respectively.

- act.fct $=$ "logistic" used for smoothing the result.

- linear.ouput=FALSE: set FALSE for apply act.fct otherwise TRUE

\section{Plotting Neural Network}

Let's plot your neural net model.

\# plot neural network

$\operatorname{plot}(\mathrm{nn})$ 


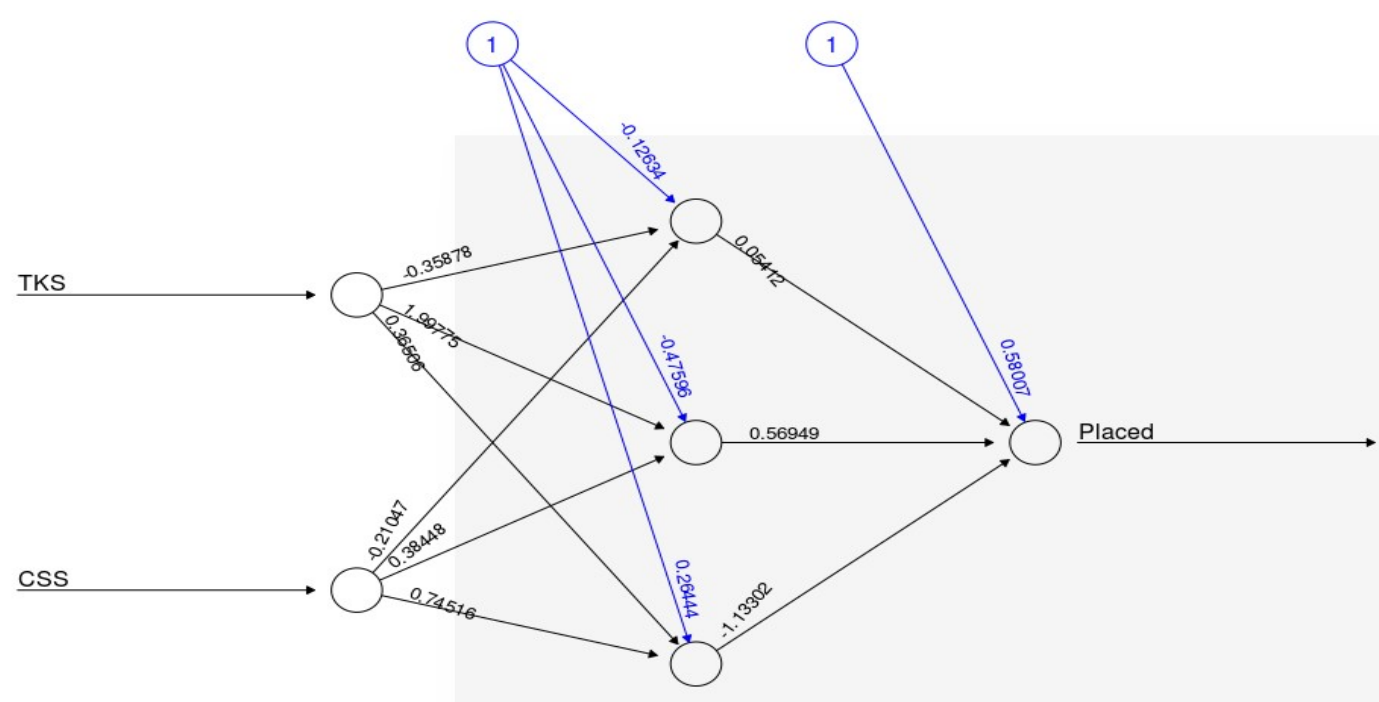

Error: 0.750054 Steps: 2

\section{Create test dataset}

Create test dataset using two features Technical Knowledge Score and Communication Skills Score

\# creating test set

$\mathrm{TKS}=\mathrm{c}(30,40,85)$

$\mathrm{CSS}=\mathrm{c}(85,50,40)$

test=data.frame(TKS,CSS)

\section{Predict the results for the test set}

Predict the probability score for the test data using the compute function.

\#\# Prediction using neural network

Predict $=$ compute(nn,test $)$

Predict\$net.result

0.9928202080

0.3335543925

0.9775153014

Now, Convert probabilities into binary classes. 


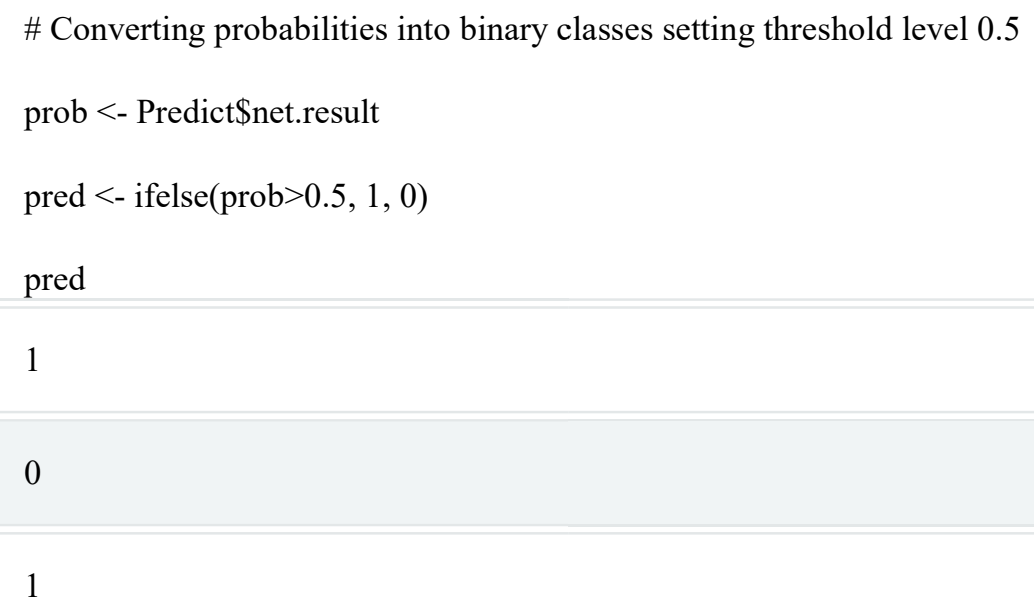

Oxygen needs estimation Another aspect of selecting the most appropriate source of oxygen is taking into consideration the gross flows of oxygen that will be needed for treatment. To determine the total flow needs, the anticipated case load has to be estimated. This can be done using the WHO COVID-19 Essential Supply Forecast Tool (ESFT). 7 From the total patients expected, the ratio of patient severity can be ascribed as outlined above: mild, moderate, severe or critical. Thus, the required flows can be estimated to meet the oxygen therapy needs for the hospitalized severe and critical patients, representing $20 \%$ of the total. About $75 \%$ of the COVID-19 patients requiring hospitalization will be classified as "severe", and $25 \%$ as "critical". Thus, the total supply of medical oxygen required can be estimated based on the recommended flow rates for each patient severity category (shown in the Table 1 below).

\begin{tabular}{|c|c|c|c|c|}
\hline \multicolumn{5}{|c|}{ Hypothetical 100 bed COVID-19 treatment facility } \\
\hline \multirow{2}{*}{$\begin{array}{l}\text { Disease } \\
\text { severity }\end{array}$} & \multicolumn{2}{|c|}{ Avg Oa flow rate } & \multicolumn{2}{|c|}{ Size of solutions of scale* } \\
\hline & per patient & Total & PSA Plant. & Bulk liquid \\
\hline $\begin{array}{l}\text { Severe } \\
75 \\
\text { patients }\end{array}$ & $10 \mathrm{~L} / \mathrm{min}$ & $\begin{array}{l}75=10-60 \\
=45,000 \mathrm{Lhr}\end{array}$ & $=45 \mathrm{~m}^{3} / \mathrm{hr}$ & $=1.25 \mathrm{~m}^{3}$ May \\
\hline $\begin{array}{l}\text { Critical } \\
25 \\
\text { patients }\end{array}$ & $30 \mathrm{LImin}$ & $\begin{array}{l}25 \times 30 \times 60 \\
=45,000 \mathrm{~L} / \mathrm{hr}\end{array}$ & $=45 \mathrm{~m}^{3} / \mathrm{hr}$ & $=1.25 \mathrm{~m}^{3} / \mathrm{day}$ \\
\hline & & & $=90 \mathrm{~m}^{3 / \mathrm{hr}}$ & $=2.5 \mathrm{~m}^{3} \mathrm{lday}$ \\
\hline
\end{tabular}

This sample scenario is based on a patient count. Typical quantification of this nature would be calculated based on availability of equipment. It is important to re-assess needs once the equipment has been commissioned, as there are likely to be equipment-specific changes in demand. All assisted ventilation implies a mix of medical air and oxygen. Flows for critical patients indicated here represent only the oxygen portion of the total gas flow required to achieve target therapeutic fraction of inspired oxygen 
(FiO2), which is the total \% oxygen in the lungs available for gas exchange. FiO2 will change over the course of a treatment, and vary from one patient to the next. The oxygen flow rate indicated here represents an average of the proportion of oxygen flows over the course of a patient's time on assisted ventilation. A simple equation to determine flow proportion at any time is as follows: Oxygen sources and distribution for COVID-19 treatment centres: interim guidance -3- TTTTTTTTTTTT FFFFFF2 = OO2 $\mathrm{LL} / \mathrm{min}+($ aaaaaa $\mathrm{LL} / \mathrm{min} x \times 21 \%$ ) TTTTTTTTTT ffffffff, $L \mathrm{~L} / \mathrm{mmmmmm}$ The WHO COVID-19 ESFT7 can also help to estimate other needs that will have to be included, such as ancillary devices,

Table 2: Description and comparison of oxygen sources and storage ${ }^{1}$

\begin{tabular}{|c|c|c|c|c|}
\hline & Cylinders & Concentrators (PSA) & Oxygen plant (PSA) & Liquid oxygen \\
\hline \multicolumn{5}{|c|}{ General characteristic } \\
\hline Image & $\mathrm{Z}$ & & & \\
\hline Description & $\begin{array}{l}\text { A refliable cylindrical storage } \\
\text { vessel used to store and transport } \\
\text { oxygen in compressed gas fom. } \\
\text { Cylinders are refilled at a gas } \\
\text { generating plant and thus require } \\
\text { transportation to and from the plant }\end{array}$ & $\begin{array}{l}\text { A self-contained, electrically } \\
\text { powered medical device designed } \\
\text { to concentrate oxygen from } \\
\text { ambient air, using PSA technology. }\end{array}$ & $\begin{array}{l}\text { An onsite oxygen generating } \\
\text { system using PSA technology. } \\
\text { which supplies high-pressure } \\
\text { oxygen throughout a facility via a } \\
\text { central pipeline system, of via } \\
\text { cylinders refilled by the plant. }\end{array}$ & $\begin{array}{l}\text { Bulk liquid oxygen generated off- } \\
\text { site and stored in a large tank and } \\
\text { supplied throughout a heath } \\
\text { facility pipeline system. Tank } \\
\text { requires refilling by liquid oxygen } \\
\text { supplier. }\end{array}$ \\
\hline $\begin{array}{l}\text { Clinical applicaton } \\
\text { andior use case }\end{array}$ & $\begin{array}{l}\text { Can be used for all oxygen needs, } \\
\text { including high-pressure supply and } \\
\text { in facilities where power supply is } \\
\text { intermittent or unreliable. Also } \\
\text { used for ambulatory service or } \\
\text { pafient transport Used as a } \\
\text { backup for other systems. }\end{array}$ & $\begin{array}{l}\text { Used to delver oxygen at the } \\
\text { bedside or within close proximity to } \\
\text { patient areas. A single. } \\
\text { concentrator can service several } \\
\text { beds with the use of a flowmeter } \\
\text { stand to split output flow. }\end{array}$ & $\begin{array}{l}\text { Can be used for all oxygen needs, } \\
\text { including high-pressure supply. }\end{array}$ & $\begin{array}{l}\text { Can be used for all oxygen needs, } \\
\text { including high-pressure supply } \\
\text { and in facilities where power } \\
\text { supply is intermittent or unreliable. }\end{array}$ \\
\hline $\begin{array}{l}\text { Distribution } \\
\text { mechanism }\end{array}$ & $\begin{array}{l}\text { Connected to manifoid of } \\
\text { centrallsub-central pipeline } \\
\text { distribution system, or directly } \\
\text { connected to patient with } \\
\text { flowmeter and tubing. }\end{array}$ & $\begin{array}{l}\text { Drect io patient with tubing of } \\
\text { through a flowmeter stand. }\end{array}$ & $\begin{array}{l}\text { Central/ sub-central pipeline } \\
\text { distribution system, or can be used } \\
\text { to refill cylinders that can be } \\
\text { connected to manifold systems in } \\
\text { the faclity. }\end{array}$ & $\begin{array}{l}\text { Central pipeline distribution } \\
\text { system. }\end{array}$ \\
\hline $\begin{array}{l}\text { Electricily } \\
\text { requirement }\end{array}$ & No & Yes & Yes & No \\
\hline $\begin{array}{l}\text { Maintenance } \\
\text { requirement }\end{array}$ & $\begin{array}{l}\text { Limited maintenance required by } \\
\text { trained technicians. }\end{array}$ & $\begin{array}{l}\text { Moderate maintenance required by } \\
\text { trained technicians, who could be } \\
\text { in-house. }\end{array}$ & $\begin{array}{l}\text { Significant maintenance of system } \\
\text { and piping required by highly } \\
\text { trained technicians and engineers, } \\
\text { can be provided as part of } \\
\text { contract. }\end{array}$ & $\begin{array}{l}\text { Significant maintenance of system } \\
\text { and piping required by highly } \\
\text { trained technicians and engineers, } \\
\text { can be provided as part of } \\
\text { contract. }\end{array}$ \\
\hline
\end{tabular}

Overabundance DELIVERY OF OXYGEN TO PATIENT

Oxygen is a medication. This assertion, in any case, seems unusual on the grounds that oxygen is ordinarily accessible in the climate on Earth constantly. So unimportant is that we continue to inhale it constantly. Be that as it may, the measure of oxygen we take in through room air is a simple $21 \%$. The air is prevailed by Nitrogen and other gasses at insignificant levels. At the point when individuals are basically sick or have persistent lung illness, they regularly require extra oxygen to oxygenate the blood and tissues appropriately. In outrageous cases, a patient may require $100 \%$ oxygen. That is to say that they are taking in unadulterated oxygen. Like all medications, an excess of oxygen can be hurtful and risky. Table 2 records the results of exorbitant openness to oxygen. There is still discussion regarding how much oxygen is a lot oxygen. We do realize that high fixations of oxygen over some time can cause an overproduction of free revolutionaries in the lungs. On the off chance that unchecked, these revolutionaries can seriously harm or slaughter lung tissue. Whenever left for a drawn out period, the patient can endure lasting lung harm. The overall standard is that a patient ought to be on minimal measure of oxygen important to keep their blood-oxygen levels sufficiently high to supply the tissues and organs enough. [14] 


\section{OXYGEN CYLINDERS DURING COVID-19 PANDEMIC}

The usage of oxygen gas gained prominence for being a prescribed item in the treatment during COVID19 times. Boosting oxygen supply is found useful in many low and middle-income countries. Oxygen infrastructure setup and maintenance are a part of the hospital setup. Hospitals in these countries have to balance immediate needs and the long-term cost-effectiveness of medical oxygen at healthcare facilities. [21] Oxygen therapy is a treatment in which the patient is given excess oxygen to facilitate easy breathing. This should be performed in the presence and instructions of trained physicians; however, as both high and low oxygen concentrations in the blood are harmful and should be monitored when administered to the human body. Thus, patients who could procure an oxygen cylinder at home should still refrain from using it themselves.[22] Media sources claimed that some patients are hoarding the cylinders in a bid to sell at higher prices to monetize the shortage situation. The act is not only immoral, illegal but also dangerous. Governments across the world insist that each oxygen cylinder be supplied, transported, and delivered to the end customer, who typically are hospitals or industrial establishments, by licensed manufacturers. Thus, hoarding oxygen cylinders is a punishable crime. Media reports across several countries have reported a three times hike in the price of oxygen cylinders. Stricter regulation and enforcement of oxygen cylinders are essential to prevent hoarding and the creation of artificial demand. Table 3 shows the business of select oxygen gas manufacturers/suppliers.

Table 3: List of leading oxygen gas manufacturers/suppliers and their business during COVID-19

\begin{tabular}{|l|l|}
\hline Company Name & Business pre/during COVID-19 times \\
\hline Linde & $\begin{array}{l}\text { The healthcare segment represents 21\% of company sales - 4 percent sales } \\
\text { growth in YoY terms. Higher medical oxygen volumes are reported, particularly } \\
\text { in Latam. Company is ramping up homecare services in Europe \& US [23] }\end{array}$ \\
\hline Air Liquide & $\begin{array}{l}1.7 \mathrm{M} \text { patients with chronic diseases are treated at home by Air Liquide in } \\
2019 .[24] 17 \% \text { of business revenue is from the healthcare business.[25] } \\
\text { Concerning H1 FY2021, globally, strong sales in Medical Oxygen are offset } \\
\text { with the postponement of elective procedures. Hygiene products and Ventilator } \\
\text { manufacturing demand continued to increase. In Europe, greater than 10\% } \\
\text { increase in sales driven by Hygiene \& Equipment but reported lower sales of } \\
\text { medical oxygen. Regarding HHC, fewer installations of new patients in sleep } \\
\text { apnea \& diabetes during the crisis. Sales in the Americas improved lead by the } \\
\text { US (at the end of Q2) and in Latin America. [26] }\end{array}$ \\
\hline Air Water & $\begin{array}{l}97 \text { percent YoY growth in revenues and 58.6 percent increase in operating profit } \\
\text { in FY2020. [27] }\end{array}$ \\
\hline Taiyo Nippon Sanso & \begin{tabular}{l} 
The company acquired IMI Co., Ltd., a medical equipment sales company. [28] \\
\hline
\end{tabular} \\
\hline
\end{tabular}


Oxygen creation in the State: Oxygen is a fundamental medication, and few sellers in India are permitted to deliver it. The oxygen creation measure fixation with few makers has brought about cost accelerations and an unreasonable stockpile of Oxygen gas. To have a reasonable market play, State Governments ought to energize interest in the area. Crowded states like Uttar Pradesh, for instance, can set up oxygen units - one each in Western, Central, and the Eastern Uttar Pradesh. Different states can utilize the overflow limit from these units.

- Expertise in oxygen assembling and supply aptitude has a tremendous effect. Henceforth, existing clinical oxygen providers having protected and ideal stockpile practices ought to be empowered.

- Assessment of Oxygen gas Supply framework: Most region level emergency clinics don't have funneled clinical gas frameworks. Notwithstanding their hefty utilization, many area clinics, significantly bigger urban areas, have a solitary chamber. Need appraisal for continuous oxygen supply framework is important at all region level clinics. Such an evaluation ought to be done no less than like clockwork or at a stretch as chosen by the wellbeing division to address interest and innovation changes.

- Establishing Oxygen request investigation and acquisition framework: Each region clinic ought to have an arrangement of evaluating/estimating Oxygen gas prerequisites. Such an appraisal ought to remember month to month or occasional varieties for oxygen utilization. An audit ought to likewise incorporate the clinical gas provider's presentation, and the District medical clinic should utilize such data for the acquisition of clinical gas.

- Oxygen observing framework: Most region emergency clinics are unfit to screen continuous oxygen supply bringing about undesirable losses at the basic consideration regions. A powerful caution framework based observing framework is important to regulate the oxygen supply in various clinic zones, particularly in basic consideration territories, to address oxygen supply deficiencies.
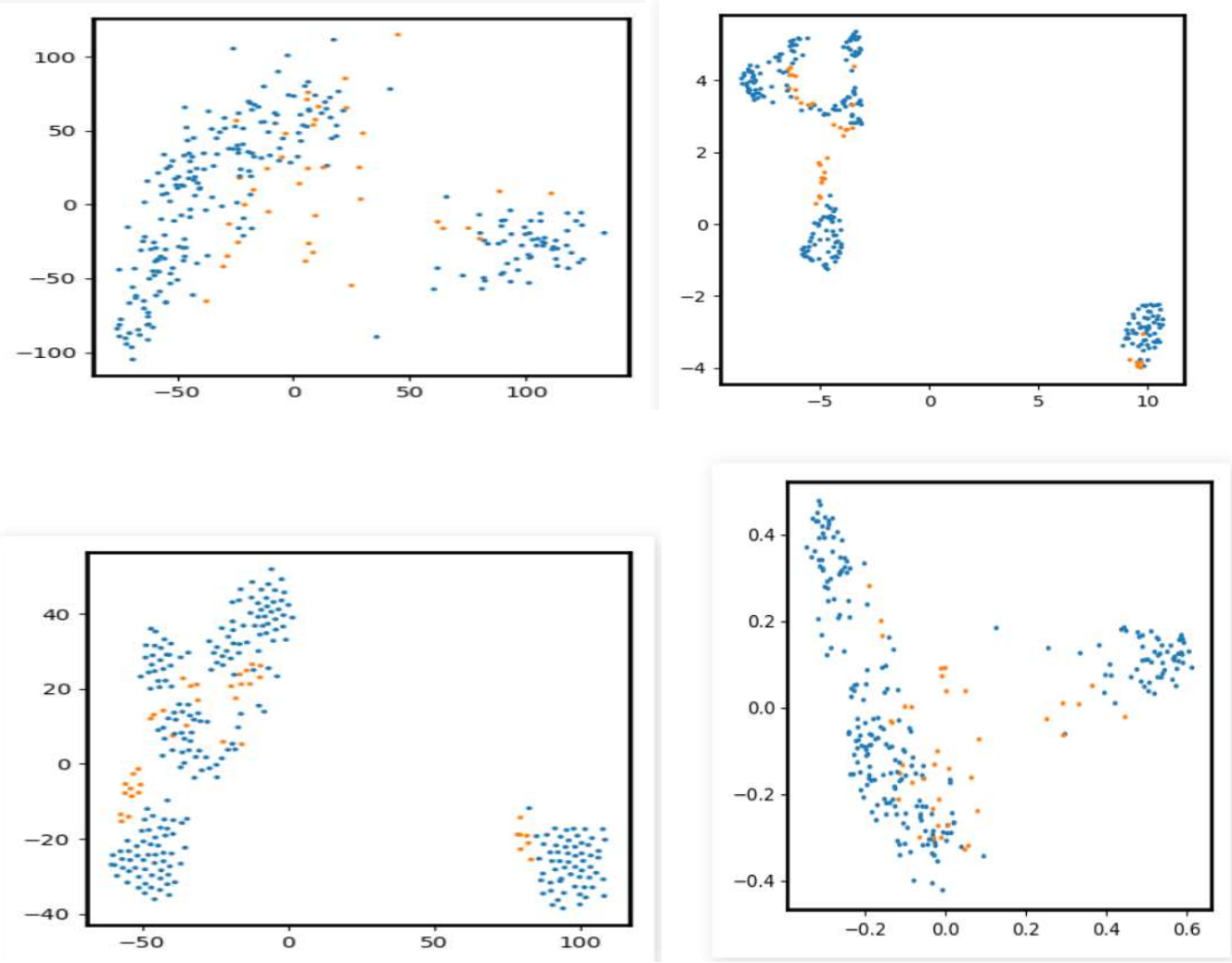

FIG- PRINCIPLE COMPONENT ANALYSIS OF MAJOR SPOT AND AVAILIBILITY 


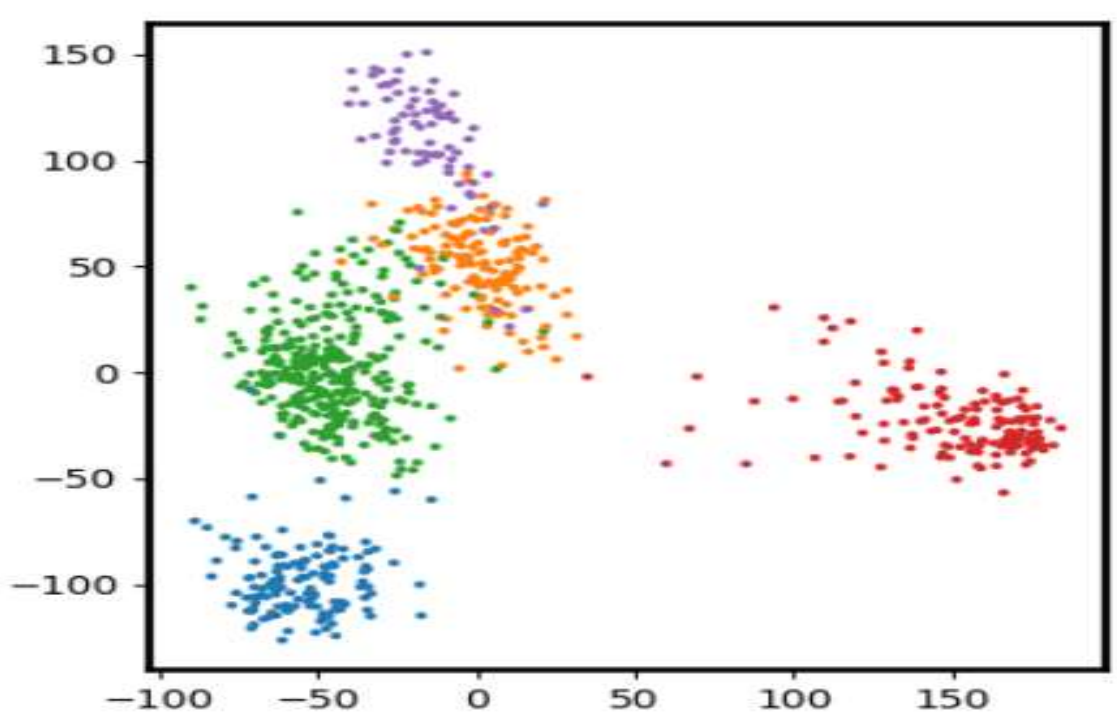

FIG - CLASSIFICATION SHOWS TYPES OF CYLINDERS USED
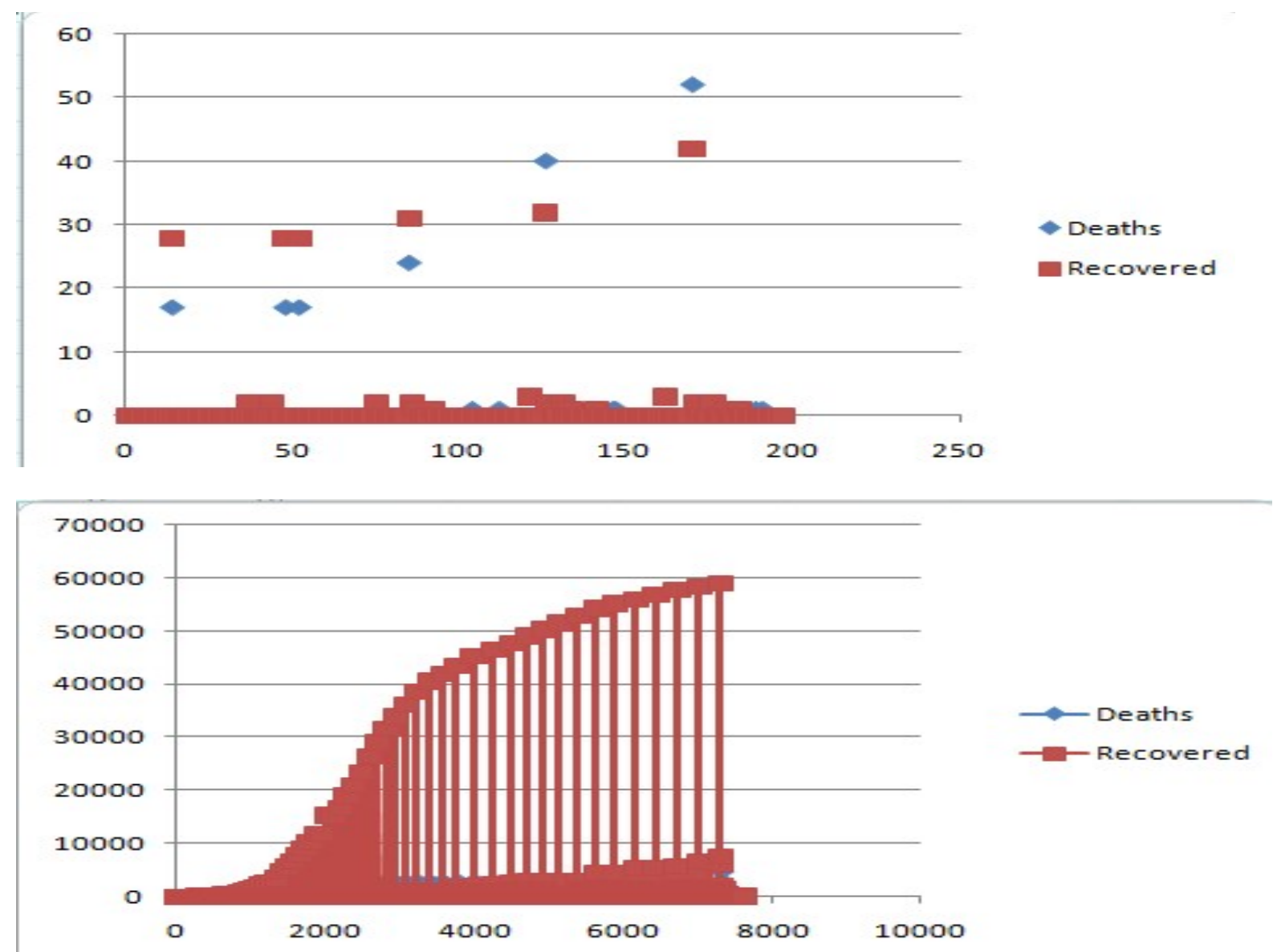

FIG- DATA SHOWS CASES RECOVERED AND DEATH DUE TO NON AVAILIBILITY OF OXYGEN GAS CYLINDERS 


\section{CONCLUSION}

The Covid-19 expanded the issues to heart patient [18] that related with the numerous different components. Then again, every one of the contaminated individuals may relieved by adequate offices. In these offices, oxygen is an innovation subordinate medication and requires successful cooperation between medical care laborers, professionals, and administrators. Improving oxygen frameworks is a feasible need for clinics in LMICs. This paper proposes functional strides to help critical and supportable upgrades in emergency clinic oxygen frameworks during the COVID-19 pandemic. Emergency clinic organization and policymakers can get learnings from this paper to move toward better oxygen admittance to patients.

In any case, biomedical designers and medical clinic professionals are much of the time avoided with regard to dynamic cycles refering to, frequently refering to absence of upkeep spending plans or framework support. Preparing, arrangement of apparatuses and extra parts, and more strong upkeep and transport frameworks can empower fix and enhancement of existing oxygen hardware and supply chains. Establishment of straightforward funneling and individual flowmeters can improve security (permitting singular titration of stream), proficiency (sharing a solitary oxygen source between various patients), and disease control (by keeping sources farther from patient regions). Counting specialists close by medical services laborers in multidisciplinary groups can help change an issue driven "oxygen migraine" into centered oxygen arrangements. We have made down to earth assets to help biomedical architects/professionals in building and keeping up solid, easy to use oxygen frameworks utilizing oxygen concentrators, chambers, flowmeter instruments/embellishments, and basic channeling. Improving patient results consistently relies on doing the nuts and bolts well. The COVID-19 pandemic offers the chance to pull together endeavors on the rudiments of intense consideration, realizing that upgrades in oxygen (and disease control, emergency, lab testing, among others) will profit patients both now and later on.

\section{REFERENCES}

1. Alexander NB, Dengel DR, Olson RJ, Krajewski KM. Oxygen-uptake (V` O2) kinetics and functional mobility performance in impaired older adults. J Gerontol A Biol Sci Med Sci 58: 734 -739, 2003. doi:10.1093/ gerona/58.8.M734.

2. American College of Sports Medicine. ACSM's Guidelines for Exercise Testing and Prescription. Philadelphia, PA: Lippincott Williams \& Wilkins, 2014.

3. Barker GA, Green S, Green AA, Walker PJ. Walking performance, oxygen uptake kinetics and resting muscle pyruvate dehydrogenase complex activity in peripheral arterial disease. Clin Sci (Lond) 106: 241249, 2004. doi:10.1042/CS20030244.

4. Beaver WL, Wasserman K, Whipp BJ. A new method for detecting anaerobic threshold by gas exchange. J Appl Physiol (1985) 60: 2020 - 2027, 1986.

5. Bell C, Paterson DH, Kowalchuk JM, Padilla J, Cunningham DA. A comparison of modelling techniques used to characterise oxygen uptake kinetics during the on-transient of exercise. Exp Physiol 86: 667-676, 2001. doi:10.1113/eph8602150.

6. Borghi-Silva A, Beltrame T, Reis MS, Sampaio LMM, Catai AM, Arena R, Costa D. Relationship between oxygen consumption kinetics and BODE Index in COPD patients. Int J Chron Obstruct Pulmon Dis 
7: 711-718, 2012. doi:10.2147/COPD.S35637. 8. Brunner-La Rocca HP, Weilenmann D, Schalcher C, Schlumpf M, Follath F, Candinas R, Kiowski W. Prognostic significance of oxygen uptake kinetics during low level exercise in patients with heart failure. Am J Cardiol 84: 741-744, 1999. 9. Buchheit M, Laursen .

8. NIH, Oxygenation and Ventilation, 2020, July 17. Retrieved from https://www.covid19treatmentguidelines.nih.gov/critical-care/oxygenation-and-ventilation/

9. Anderson T. COVID 19 and the oxygen bottleneck. Bull. World Health Organ. 2020;98:586-587. doi: 10.2471/BLT.20.020920. [MC free article] [PubMed] [CrossRef] [Google Scholar]

10. Inmatec, Medical Oxygen, 2020. Retrieved from https://www.inmatec.de/en/medical-oxygen.html

11. Markets and Markets Medical Gas and Equipment Market. 2020. https://www.marketsandmarkets.com/Market-Reports/medical-gases-equipment-market217979261.html Retrieved from.

12. PESO. (2020). Retrieved from https://peso.gov.in/web/about-peso

13. WHO, Oxygen sources and distribution for COVID-19 treatment, 2020.

14. Smith L., Baker T., Demombynes G., Yadav P. Center for Global Development; 2020. COVID-19 and Oxygen: Selecting Supply Options in LMICs that Balance Immediate Needs with Long-Term CostEffectiveness. [Google Scholar]

15. The Gazette of India, Ministry of Road Transport and Highways, 2020.

16. T. Barnagarwala, Several districts in Maharashtra plan own plants. Indian Express, 2020, September 13.

17. M. Ghazali, Punjab Asks Neighbouring States To Increase Supply Of Liquid Oxygen. NDTV, 2020, September 14. Retrieved from https://www.ndtv.com/india-news/coronavirus-punjab-asks-neighbouringstates-to-increase-supply-of-liquid-oxygen-2294855.

18. Diwakar Manoj, Tripathi Amrendra, Joshi Kapil, Memoria Minakshi, Singh Prabhishek, kumar Neeraj. Latest trends on heart disease prediction using machine learning and image fusion. Mater. Today: Proc. Elsevier. 2020 doi: 10.1016/j.matpr.2020.09.078. [CrossRef] [Google Scholar] 